\title{
SOCIAL MEDIA AND CHEATING: IS THERE A NEED TO REVIEW YOUR ACADEMIC INTEGRITY POLICY?
}

\author{
Philip Kim, Walsh University, pkim@walsh.edu \\ Joseph V. Homan, Monterey Technologies, Inc., jhoman@montereytechnologies.com
}

\begin{abstract}
Social media use continues to rise in today's academic institutions. Along with the ubiquity of social networking platforms, social media usage continues to grow among students, industry professionals, and colleges and universities. Although social media adoption and use have experienced rapid growth over the past decade, there is still some uncertainty regarding its place in the classroom. Even further, there is a growing concern that open networks and a collaborative learning environment could unintentionally lead to a violation of the school's academic integrity policies. Faculty members should consider revising their academic integrity policies to explicitly include the use of social media sites, expected behavior, and consequences of policy violations.
\end{abstract}

Keywords: Social Media, Collaboration, Academic Integrity Policy, Cheating, Social Media Policy

\section{INTRODUCTION}

Social media is a pervasive aspect of modern culture. According to the Global Web Index, the total number of active social media users in 2019 is more than 3.4B users for a 45\% penetration of the global population (Chaffey, 2019). Along with the ubiquity of mobile devices, social media usage continues to grow among young adults. In particular, young adults (18-24 years) have been reported to use a variety of different platforms but primarily utilizing Instagram, Snapchat, YouTube, and Facebook (Perrin \& Anderson, 2019). As such, many academic institutions have adopted social media as a tool to reach and recruit potential students (Rahmati, 2016). However, even though social media has experienced rapid growth over the past decade, there is still some uncertainty surrounding its place in higher education curricula. Many faculty members are unsure of how to use social media effectively and their efforts are often scattered and unfocused (Dzvapatsva, Mitrovic, \& Dietrich, 2014). In recent years, social media research has placed an emphasis on collaborative learning and to engage students more effectively (Chawinga, 2017). While traditional teaching methods such as in-class face-to-face interaction and lecture offer many advantages, there are obvious time and physical space limitations (Gikas \& Grant, 2013). Additionally, industry leaders are increasingly adopting social media technologies for use as collaborative learning tools and communication platforms for their employees (Awolusi, 2012). For professional programs, such as business, MIS, and CS this presents a unique but welcome challenge. How can university faculty encourage the use of current social media platforms for collaborative learning, team building, and communication, while still maintaining and enforcing the academic integrity policies? The review of the literature yielded limited results for the use of social media platforms and adherence to academic policy standards. This paper explores how social media could lead to both intentional and unintentional violations of academic integrity.

\section{Evolution of Social Media in the Classroom}

During the relatively short time that social media has been in existence, it has evolved from a source of connection to family and friends and social networking to an accepted form of online communication in which many students choose to participate in (Reimherr, 2014). Social media began to gain traction in 1997 when a newly launched site called Six Degrees allowed users to create a profile and find friends, a play upon the 'six degrees of freedom' theory. Following the emergence of Six Degrees, blogging and instant messaging became a popular way for individuals to use the internet for social networking. The permeation of the internet grew throughout the early 2000s, and in 2003, MySpace became a popular social media platform for users to create a profile and communicate with friends online. In 2004, Mark Zuckerberg launched Facebook as a way for Harvard students to create profiles and connect with each other. As it became popular at Harvard, Zuckerberg and external investors recognized its broader potential and created the site for anyone to use (History, n.d.). 


\section{Issues in Information Systems \\ Volume 20, Issue 3, pp. 22-27, 2019}

Twitter was created in 2006 in response to the popularity of smartphones and text messaging. Twitter was unique because it allowed users to communicate with the world by sending out messages or tweets of 140 characters or less. In 2010, when Facebook and Twitter were well established in the market, many new social media platforms emerged, including photo sharing sites like Photobucket and Instagram, as well as microblogging sites like Tumblr and Plurk. It was also during this timeframe that social media became prominent on many college campuses. Colleges and universities have continued to use social media profiles for marketing and recruiting efforts. Today, an increasing number of higher education institutions are learning to use social media platforms to connect with consumers and market their products and services (Campbell, 2010). Especially in the past decade, social media has experienced substantial growth for young adults. A 2019 report concluded that more than $91 \%$ of young adult Americans had at least one social media profile, up from less than 75\% in 2009 (Perrin, 2015; Perrin \& Anderson, 2019).

The impact that social media has had on education is significant. While technology in the classroom was traditionally viewed as a way for users to consume content, Web 2.0 and social media has become more of a platform for students to create and share content. Individuals often use their social media accounts to share and discuss their opinions of schools, programs, and complaints (Gensler, Völckner, Liu-Thompkins, \& Wiertz, 2013). This can have a significant effect on a school's reputation. This is the social media phenomenon: there has been a power shift from the hands of the business to the hands of the consumers of the brand (Berthon, Pitt, Plangger, \& Shapiro, 2012). The same is true about academia. The ivory tower is showing its cracks and people are sharing their stories, both positive and negative, in their social networks.

\section{Social Media in the Classroom}

With the majority of young adults participating in social media, there is no question of its importance within today's classroom. However, with its rapid growth, there is much uncertainty surrounding it, especially related to curriculum. Some still question whether social media should be used in the classroom instruction, and if so, in what capacity? While many university marketing departments, athletic departments, admissions offices, and coaches have chosen to dive into social media by creating profiles on many platforms, a number of faculty are unsure of how and where exactly to integrate social media into their courses, assignments, and other formative assessments. This lack of understanding of social media's forms and purposes has caused a sense of resistance related to whether social media should be an integral part of a learning strategy (Bergland, 2014). Greenhow, et al. (2017) argue that while faculty are well versed in those fields in which social media is used (e.g. journalism, marketing, business), it has failed to gain widespread acceptance in mainstream academia.

\section{Social Media in Business}

Surprisingly, even corporate leaders and decision-makers in business are often disorganized about the purpose of social media in business. For example, how can it be integrated into the company's strategy and how should resources be allocated? Although most companies have social media accounts, their efforts are rarely focused enough to achieve maximum efficiency in communicating with their target consumers. Firms should conduct a thorough social media audit in order to clean up their participation in social media and choose only the platforms that target their specific markets (Feigenbaum, 2018). Research also suggests the importance of ensuring that all of the firm's social media activities are aligned with its promotional strategy (Safko \& Brake, 2009). Companies can increase and retain their actively engaged consumers when they proactively respond to those who show interest in their products and services (Kaplan \& Haenlein, 2009). They also suggest that firms maintain a tone of humility and relatability and avoid being too professional to truly connect with consumers (Patel, 2015). How can these same concepts and principles be integrated into business courses?

As this research suggests, social media has been leveraged by the business community as a marketing and public relations tool, to gain better insight and access to consumers. The vast majority of current research aims to explore how companies can better utilize social media to engage their customers. However, there is a smaller amount of research which suggests how those same social media tools can be utilized as a knowledge sharing tool. Internal social media networks allow employees faster access to information and solutions to support their respective projects. Social media technologies can be used to create a centralized hub of information and knowledge where employees can quickly and efficiently access the information they need. All posted content is accessible, organized, and searchable to all who would potentially need it. The impacts of implementing such a platform have the potential to dramatically reduce valuable time spent reviewing e-mail and attending meetings. Content posted by individual employees also can be tracked (Chui et al, 2012). These social platforms can also be used as a talent matching tool to place certain 


\section{Issues in Information Systems}

Volume 20, Issue 3, pp. 22-27, 2019

employees in better fittings roles and recognize them for their work. Matching the correct skill set with the right position will naturally increase productivity as well. Additionally, the new communication and collaboration capabilities derived from an enterprise social network have the potential to improve and change the onboarding process of new employees and external partners, suppliers, and vendors. New employees would spend less time searching for answers and tracking down an internal expert because all the information would be in an organized and searchable location. The benefits of implementing and utilizing a social media platform are obvious to most employers. As such, there is the potential for faculty members to mimic and copy social media engagement strategies in business without proper measures to ensure academic integrity issues such as cheating, plagiarism, and sharing of unauthorized resources. In the context of creating a collaborative and open learning environment, perhaps faculty members have overlooked the potential of academic fraud and dishonesty. Yes, social media platforms may further permeate the workplace in the future, but so do professionalism and professional codes of conduct. Even in the workplace, performance evaluations are still assessed on an individual basis. Most employees are assessed for the work they complete. This should also remain true for students. Even with group projects and team-based learning, students should be assessed based on their distinct contribution in the classroom.

\section{Open Communication and Collaboration}

One of the key benefits realized from social media technology is improved communication and collaboration across an organization. Collaboration often happens within an informal group of individuals (Awolusi, 2012). This indicates that the rigidity of hierarchical reporting structures that are placed around students and professors is not where idea generation and collaboration is taking place. Faculty and course designers can often ignore the benefit of informal networks and informal collaboration taking place. Research indicates that such informal networks consistently provide both "strategic and operational value" to the larger group (Cross, Borgatti, \& Parker 2012). Social media technologies have the ability to act as a catalyst in generating increased informal collaboration. It would serve as an additional medium for communication between members of an informal network with the speed and scale of internet and information and communication technologies. Collaboration and communication can drive knowledge sharing and idea generation within a classroom. Knowledge sharing involves helping others comprehend a given topic, communication to solve daily issues, generating new ideas, and developing innovative solutions to complex problems (Gaal, Szabo \& Obermayer-Kovacs, 2015). This is important within any industry but is crucial for coursework as students are participating in a knowledge-intensive environment. Knowledge-intensive environments require collaboration among and across many groups with different knowledge bases and skill sets. Collaboration among diverse groups can help drive problem-solving and idea generating as well (Cross, Borgatti \& Parker 2012). Social media platforms afford the opportunity for students to work with other students across different majors, programs, and universities in a global environment. Many students are also encouraged to join professional networking and industryrelated professional society groups. There are countless opportunities for students to join and participate in professional society groups, discussion forums, and to join subject matter experts on Facebook, Instagram, Reddit, and LinkedIn.

\section{Potential Pitfalls of Social Media in the Classroom}

Although social networks and their corresponding benefits continue to be explored, there are several risks when faculty members allow students to access such technologies. While cheating in higher education is nothing new, the rate at which student admit to academic dishonesty is surprising. In a recent survey, over $85 \%$ of college students admitted to cheating at least once while in school (Farkas, 2018). Over 95\% of admitted cheaters say they have never been caught, while only $12 \%$ of those surveyed indicated they would never cheat because of ethical concerns (Farkas, 2018). Within the communication sciences and disorders (CSD) discipline, there are many social media groups. CSD students are encouraged to join these groups and to add to the discussion. Under the guise of mentorship or asking for advice, the following questions were posed by students:

- Doing an assignment, and I got stuck on this question for a long time. Does anyone have a good explanation for this?

- I need help with an assignment, and my professor is not responding on our discussion board at this time. Can someone tell me what the severity should be? 


\section{Issues in Information Systems}

Volume 20, Issue 3, pp. 22-27, 2019

- I desperately need help with this if anyone is available to help. I'm guessing sensorineural hearing loss, but I am also leaning towards mixed. (Newkirk-Turner, Johnson, \& Vaughan-Robinson, 2019, p.8).

Ironically, because these professional social networking groups are designed to be open and collaborative, these queries generate numerous responses. Often these posts are accompanied by a screenshot of the professor's assignment as well. In the spirit of being helpful or wanting to share knowledge, many professionals do not consider the potential harm to the student. Beyond just giving the student the correct answer, this circumvents the learning process. There are times when students benefit from not having instant access to the solution. It forces the learner to engage the material, to dig deeper, and to acquire competence and research skills that go beyond the benefit of just getting the right answer. Similar to the pedagogical method of requiring students to 'show their work' rather than selecting the correct multiple-choice answer.

\section{Policy Change}

Social media technologies have evolved tremendously since initial development. What began as a source of online communication is now also being used as a didactic tool to engage students, promote collaboration, and directly connect students with each other, faculty, and other external stakeholders. While social media technologies can be used for educational purposes, many faculty members have not accounted for the potential hazards they present.

Newkirk-Turner et al (2019) suggest the following guidelines for faculty and academic programs:

1. Set clear expectations about academic dishonesty. Clearly define examples of cheating and plagiarism while using social media examples. This should be done at the beginning of the semester and periodically reviewed throughout the semester.

2. Develop a social media policy. The policy should clearly outline academic dishonesty and include sanctions in the event of a code violation. Some exemplars are:

a. The University of Iowa's College of Liberal Arts and Sciences Academic Honesty Policy (includes social media, definitions, examples, and consequences for infractions).

b. The University of Houston's Department of Communication and Sciences and Disorders social media policy.

c. The University of Melbourne Academic Integrity social media policy.

3. Carefully monitor professional social media groups. As a faculty member, you should consider joining these groups and encouraging founding members and moderators to establish rules regarding academic integrity.

\section{CONCLUSION}

Social media has the potential to become a new classroom productivity tool within schools and departments. They allow students and faculty to streamline systems and processes, generate idea sharing, centralize pertinent content and information, and ultimately increase collaboration across an enterprise. McKinsey \& Co. (2012) estimates that organizations that effectively introduce social media platforms into business processes have the potential to increase productivity by 20 to 25 percent (Chui et al, 2012). The increased productivity could result in significant value creation for students and their academic programs. But it must be done in a way that protects the integrity of the institution and the learning process of the students. Due to the growth potential of social media sites, it is important for faculty and administration to be prepared for the inevitable proliferation of such technologies. Faculty members that successfully leverage and integrate social media platforms into the classroom have the potential to help their students learn at a more dynamic pace that is on par with what is already being utilized in industry. However, in light of these advantages, it is recommended that faculty consider how to integrate social media platforms while maintaining the academic integrity policies to ensure an optimal and equitable learning environment. 


\section{Issues in Information Systems}

Volume 20, Issue 3, pp. 22-27, 2019

\section{REFERENCES}

Awolusi, F. (2012, January). The Impacts of Social Networking Sites on Workplace Productivity. The Journal of Technology, Management, and Applied Engineering, 28(1), 1-5.

Bergland, C. (2014). The "Ivory Tower" Appears Reluctant to Use Social Media. Psychology Today. Retrieved from: https://www.psychologytoday.com/us/blog/the-athletes-way/201403/the-ivory-tower-appearsreluctant-use-social-media.

Berthon, P. R., Pitt, L. F., Plangger, K., \& Shapiro, D. (2012). Marketing meets Web 2.0, social media, and creative consumers: Implications for international marketing strategy. Business Horizons, 55(3), 261-271.

Campbell，D. (2010). "The New Ecology of Information: How the Social Media Revolution Challenges the University. Environment and Planning EPD: Society and Space 28(2), 193-201.

Chaffey, D. (2019). Global social media research summary 2019. Smart Insights. Retrieved from: https://www.smartinsights.com/social-media-marketing/social-media-strategy/new-global-social-mediaresearch/.

Chawinga, W. D. (2017). Taking social media to a university classroom: teaching and learning using Twitter and blogs. International Journal of Educational Technology in Higher Education, 14(3).

Chui, M., Manyika, J., Bughin, J., Dobbs, R., Roxburgh, C., Sarrazin, H., Sands, G., Westergren, M. (2012, July). The Social Economy: Unlocking Value and Productivity through Social Technologies. McKinsey Global Institute, 6-48.

Cross, R., Borgatti, S. P., \& Parker, A. (2012). Making Invisible Work Visible: Using Social Network Analysis to Support Strategic Collaboration. California Management Review, 44(2), 25-45.

Dzvapatsva, G. P., Mitrovic, Z., \& Dietrich, A. D. (2014). Use of social media platforms for improving academic performance at Further Education and Training Colleges. South African Journal of Information Management, 16(1).

Farkas, K. (2018). 86 percent of college students say they've cheated. It's easier than ever with mobile devices. Retrieved from: https://www.cleveland.com/metro/2017/02/cheating_in_college_has_become.html.

Feigenbaum, C. (2018). Why You Need to Perform a Social Media Audit. Social Analytics. Retrieved from: https://www.netbase.com/blog/why-you-need-to-perform-a-social-media-audit.

Gaal, Z., Szabo, L., \& Obermayer-Kovacs, N. (2015). The Power of Social Media in Fostering Knowledge Sharing (pp. 114-121, Rep.). Academic Conferences \& Publishing International.

Gensler, S., Völckner, F., Liu-Thompkins, Y., \& Wiertz, C. (2013). Managing brands in the social media environment. Journal of Interactive Marketing, 27(4), 242-256.

Gikas, J. \& Grant, M.M. (2013). Mobile computing devices in higher education: Student perspectives on learning with cellphones, smart phones and social media. Internet and Higher Education, 19, 18-26.

Greenhow, C., Gleason, B., Marich, H., Staudt Willet, B. (2017). Educating social scholars: Examining novice researchers' Practices with Social Media. Qwerty. Open and Interdisciplinary Journal of Technology, Culture and Education, 12(2).

History of Social Media. (n.d.). Retrieved March 10, 2019, from http://historycooperative.org/the-history-of-socialmedia. 


\section{Issues in Information Systems}

Volume 20, Issue 3, pp. 22-27, 2019

Kaplan, A. M., \& Haenlein, M. (2010). Users of the world, unite! The challenges and opportunities of Social Media. Business Horizons, 53(1), 59-68.

Patel, S. (2015, June 24). How Businesses Should Be Using Social Media in 2015. Retrieved March 10, 2019, from http://www.forbes.com/sites/sujanpatel/2015/06/24/how-businesses-should-be-using-social-media-in2015/\#7a7aafd24a5b.

Rahmati, R. (2016). How Social Media is Changing College Recruiting. Retrieved from: https://www.spredfast.com/social-marketing-blog/how-social-media-changing-college-recruiting.

Reimherr, D. (2014). Social Networking: College Students and Social Media Statistics. Retrieved from: https://shweiki.com/blog/2014/02/social-networking-college-students-social-media-statistics.

Safko, L., \& Brake, D. (2009). The Social Media Bible: Tactics, Tools, and Strategies for Business Success. Choice Reviews Online, 47(01). 